\title{
DIDÁTICA E A FORMAÇÃO DE LICENCIADOS EM GEOGRAFIA: UMA ANÁLISE DE SUAS FRAGILIDADES
}

\author{
André Ferreira \\ Aluno do $7^{\circ}$ período do Curso de Geografia da UFRN \\ Carla Mirelly Caetano Duarte \\ Aluna do $7^{\circ}$ período do Curso de Geografia da UFRN \\ Igor Silvestre dos Santos \\ Aluna do $7^{\circ}$ período do Curso de Geografia da UFRN
}

\section{Resumo}

Esse presente artigo tem como objetivo discorrer sobre a importância da didática no processo inicial de formação de professores, externando algumas apreensões dos docentes de Geografia acerca das fragilidades encontradas em seu processo formativo, que influem diretamente em suas práticas diárias escolares. Para tal, realizamos revisões bibliográficas acerca do tema, e aplicamos um questionário online via Google Forms, a fim de obter as informações necessárias. Assim analisamos os dados obtidos, e relacionamos com os referenciais teóricos.

Palavras-Chaves: Educação Geográfica. Didática. Formação do Professor.

\begin{abstract}
This article aims to discuss the importance of didactics in the initial process of teacher training, expressing some concerns of Geography teachers about the weaknesses found in their formative process, which directly influence their daily school practices. To do this, we carry out bibliographic reviews on the subject, and apply an online questionnaire via Google Forms in order to obtain the necessary information. Thus, we analyze the data obtained, and relate them to the theoretical references.
\end{abstract}

Keywords: Geographic Education. Didactics. Teacher Training. 


\section{INTRODUÇÃO}

O modo de compreensão do âmbito escolar, e o ensino de geografia deve possibilitar ao aluno mecanismos que possibilitem o entendimento do Espaço Geográfico. Nesse processo, o docente tem uma importância singular, atuando muito mais que um transmissor de conteúdo, mas como um mediador para apreensão da totalidade espacial. No entanto, em muitos casos o objetivo da Geografia Escolar não tem se efetivado em seu âmbito em virtude de diversas dificuldades, uma dessas é apontada como fragilidades na formação do docente.

Nesse arcabouço, procuramos entender a contribuição da didática para efetivação da prática docente no Espaço Escolar. Assim, objetivamos compreender as necessidades da formação de professores licenciados em Geografia, apreendendo a importância da didática no processo de formação inicial e identificando as necessidades de formação apontadas pelos professores entrevistados.

Portanto, inicialmente apresentaremos a metodologia, posteriormente as análises dos dados - evidenciando as reflexões, e análises das respostas das entrevistas relacionadas com os referenciais teóricos -e, por fim, as considerações finais retomando de forma sintética o que já foi escrito, destacando algumas conclusões e contribuições para licenciatura em Geografia, apontando perspectivas futuras de continuidade de estudos, pesquisas e demais atividades acadêmicas.

\section{METODOLOGIA}

A metodologia da pesquisa remeteu-se à aplicação de questionários e análises bibliográficas. Aplicamos dezesseis questionários, online, através da ferramenta Formulários, do Google Docs. Nessa pesquisa, participaram professores atuantes no nível básico e superior ( 13 homens e 3 mulheres), e como resultado, foram gerados dados quantitativos e qualitativos. Posteriormente, relacionamos suas respostas com os referenciais teóricos, apontando nossas reflexões e análises.

Os profissionais entrevistados são licenciados em Geografia, formados majoritariamente pela Universidade Federal do Rio Grande do Norte e atuantes no nível secundário. Sendo um dos entrevistados formado pelo Instituto Federal do Rio Grande do Norte (IFRN) e outro pelo Centro Universitário de Jales - SP. A variação dos anos de formação está entre 1997 e 2015. Nessa pesquisa contamos também com a presença de graduados, mestres, mestrandos e doutores em Geografia. Em termos de tempo de atuação profissional, $62 \%$ dos entrevistados, ou seja, dez professores estão atuando em sala de aula entre um e cinco anos, dois entre seis e dez anos, e quatro com mais de onze anos em sala de aula. Como podemos observar no gráfico 1:

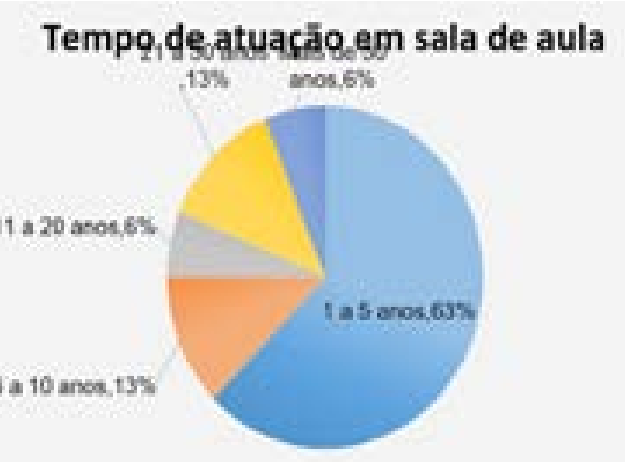


Assim constatamos que, apesar da variação do tempo de atuação, diferentes épocas de formação, e até mesmo das diferentes realidades no âmbito profissional, o grupo evidenciou fragilidades e discursos em comum. Nesse sentido, no próximo tópico explanaremos a relação dos dados obtidos com a pesquisa e os referenciais teóricos.

\section{REFLEXÕES ACERCA DA PESQUISA}

A formação docente ainda é um dos grandes desafios da educação brasileira, apesar dos avanços vividos na sua história, sendo apresentada por muitos como frágil e sem êxitos, e os professores como despreparados, e meros transmissores de conteúdo, como afirma, Pontuschka, 2009, p.89:

[...] os cursos de formação docente têm historicamente demonstrado sua falta de êxito, reforçando o estereótipo segundo o qual se trata de cursos fracos. Os professores, via de regra, são vistos como profissionais despreparados, sem capacidade degerir autonomamente os próprios saberes.

Nesse sentido, identificamos que as fragilidades no processo formativo interferem diretamente na prática docente, dificultando ou até mesmo impedindo a plena realização do processo "ensinar e aprender". Principalmente no que se refere à utilização de recursos didáticos que transmitam de forma acessível o conteúdo aos alunos do ensino básico. Observe o gráfico 2.

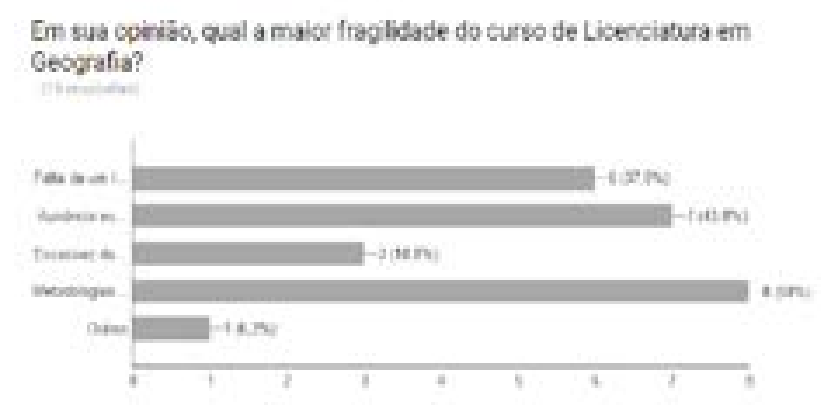

Gráfico 2: Fragilidades do curso de licenciatura em Geografia.

Ao analisar o gráfico 2, percebemos que, no recorte feito, a maior fragilidade do curso de licenciatura em Geografia são as metodologias de formação do licenciado. Ao ingressar no curso da modalidade Licenciatura, numa Instituição de Ensino Superior (IES), espera-se que durante a graduação, metodologias para futuras ações dentro do lócus escolar sejam transmitidas e comprovadas. Onde o licenciado adquira habilidades mínimas para mediar junto aos alunos compreensão teórica dos temas abordados, e que venham a "espacializálos" na prática.

Os entrevistados destacaram algumas falhas em sua formação para melhores práticas como docente em Geografia, que foram: capacitação dos professores universitários, envolvendo a falta de atualização de metodologias, categorias e conceitos da geografia; a falta de um maior aprofundamento no campo teórico geográfico; divergência entre conteúdos acadêmicos com as escolas de base onde atuam, e, principalmente, a ausência de disciplinas que remetessem as metodologias e instrumentalização do ensino de Geografia. 
Em virtude disso, os professores evidenciaram que suas práticas são afetadas na medida em que não sabem utilizar geotecnologia aplicada ao ensino; não têm segurança na elaboração de um plano de aula; como também sentem dificuldades em lidar com alunos especiais, apesar de ter cursado disciplinas direcionada a proposta de inclusão, como libras e introdução a educação especial.

Com isso, os entrevistados ficam presos ao modo "tradicional": quadro, giz e livro didático. Confessando direta ou indiretamente que se tivessem tido uma melhor formação, essa situação poderia ser diferente. Nesse sentido, a lacuna que existe na formação docente no curso de geografia, no que tange à aplicação da didática em sala de aula, foi exposta pelos entrevistados como algo que necessita de um olhar mais apurado.

Esse processo de ser e se tornar professor vai se construindo desde os primeiros contatos dos indivíduos com as chamadas fontes pré-profissionais do saber ensinar (TARDIF; RAYMOND, 2000), passando por experiências como alunos em seus cursos de formação inicial, até as futuras interações desse profissional com as características das instituições escolares, onde atuam ou irão atuar, com outros profissionais. Então, o processo de formação inicial torna-se fundamental para os futuros professores, pois os elementos das componentes curriculares se constituirão como alicerces para o processo de ensinoaprendizagem dos educadores.

Na formação pedagógica dos professores, a Didática tem de merecer atenção especial e deve ser concebida como de alta relevância para a construção de uma escola de maior qualidade. Busca, assim, práticas pedagógicas que tornem o ensino de fato eficiente (não no sentido da qualidade total) para a maioria da população. (DALBERIO, Maria. DALBERIO, Osvaldo. 2010. p. 10).

A Didática apresenta-se como uma das componentes essenciais para a formação do professor e que ocupa um lugar de destaque no que diz respeito ao "que fazer" na construção da prática pedagógica (CANDAU, 2012). Para esclarecer qualquer dúvida sobre o papel desta componente, Maria Dalberio e Osvaldo Dalberio (2010), prosseguem reafirmando sua importância na formação do profissional da educação e de que forma ela ajuda a desmitificar o ensino, assim como solucionar questões do cotidiano escolar, futuro dos professores em formação:

[...] a Didática tem como objetivo a compreensão dos diferentes determinantes da prática pedagógica e a construção de forma que possa nela intervir no sentido de favorecer a formação de sujeitos mais reflexivos, críticos e comprometidos com uma democracia real, para todos (DALBERIO, p. 98, 2010).

Dessa forma, Luckesi (2012, p. 29) discute o papel da didática na formação trazendo a seguinte questão: "Será que a didática, conforme vem sendo ensinada e executada, auxilia o educando a se habilitar para as atividades que deverá desenvolver como futuro educador?". Através desta perspectiva, pode-se observar que a didática tem sido encarada apenas como um "facilitador" que transmitirá os conteúdos e atividades referentes a conhecimentos específicos, que muitas vezes estão dispostos em livros didáticos, apenas reforçando ideologias dominantes. Com isso, ele traz a seguinte observação: 
Penso que a didática, para assumir um papel significativo na formação do educador, deverá mudar os seus rumos. Não poderá reduzir-se e dedicar-se tão somente ao ensino de meios e mecanismos pelos quais se possa desenvolver um processo de ensino-aprendizagem, mas deverá ser um elo fundamental entre as opções filosófico-políticas da educação, os conteúdos profissionalizantes e o exercício diuturno da educação. Não poderá continuar sendo um apêndice de orientações mecânicas e tecnológicas (LUCKESI, 2012, p. 33).

Posteriormente ele encerra sua visão de como a didática deveria ser contemplada no processo de formação: "Deverá ser, sim, um modo crítico de desenvolver uma prática educativa, forjadora de um projeto histórico, que não se fará tão somente pelo educador, conjuntamente, com o educando e outros membros dos diversos setores da sociedade" (LUCKESI 2012, p. 33).

Todos os entrevistados consideram a didática essencial para formação de professores (gráfico 4). No entanto, somente 12;5\% dos entrevistados afirmaram que a didática recebia o merecido no destaque, $25 \%$ disseram que não recebia destaque e $62,5 \%$ dos entrevistados disseram que em sua época de formação a didática era explorada e recebia destaque dentro do processo formativo razoavelmente (gráfico 5). Sem dúvidas podemos aferir que a utilização da didática como caminho para abordagem dos conteúdos é fundamental para uma otimização do desenvolvimento no âmbito escolar. Para tanto, é necessário que o docente a conheça profundamente para que seu uso como ferramenta seja um catalisador na aplicação do seu ofício. Observa-se que a importância devida da disciplina didática não foi realizada com eficácia, permitindo a formação de uma lacuna na docência.

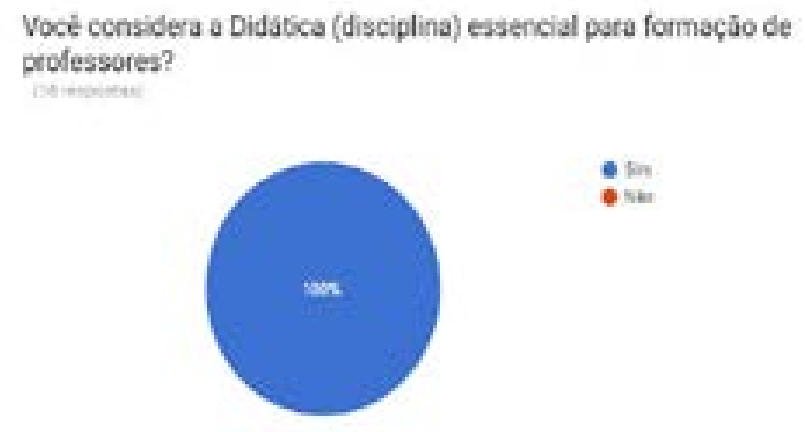

\section{Gráfico 3}

Os entrevistados classificaram como importante a didática para sua formação, visto que é utilizada como uma fundamental ferramenta dentro do processo de ensinoaprendizagem. É essencial para desenvolver a aplicação dos recursos didáticos nas atividades do cotidiano escolar. O entrevistado P11 expôs que:

"A didática foi uma disciplina imprescindível para o meu processo de formação em licenciatura em Geografia. Pois é através dela que aprendemos a organizar e sistematizar tanto conteúdos como metodologias de ensino mais adequadas para alcançar os objetivos propostos em nossos planos de aulas e atividades desenvolvidas. Depois que a cursei, é que pude me identificar mais enquanto docente, pois em outras disciplinas, também direcionadas para o eixo educacional, nem sempre conseguia identificar esse propósito da maneira de "como ensinar", e a execução de nossas práticas já aplicadas ao cotidiano escolar." 
Na prática profissional, inclusive no relacionamento aluno/professor se faz necessário a eficácia do uso otimizado da didática. É à base da função do professor como um mediador do conhecimento, facilitando a interação do aluno com o conteúdo, e com o professor. Desse modo, devendo relacionar a metodologia à prática, com objetivo de facilitação do aprendizado. $O$ entrevistado P15 relatou que:

"A didática é importante para o aperfeiçoamento das metodologias de ensino e a forma como as aulas são conduzidas no que cerne o ensino-aprendizagem dos alunos, além disso, aprimoramento da formação continua do docente."

Enquanto o entrevistado $\mathrm{P9}$ ressaltou que:

"No meu curso a importância foi mínima, o professor foi muito superficial o que fragilizou minha formação nessa disciplina."

Assim, podemos reafirmar que a didática e sua aplicação é de enorme importância para o exercício da docência. 0 que diz Barroso, (1997) é "que o trabalho modifica o saber trabalhar do professor". Os saberes a serem ensinados pelos professores e o seu modo de ensinar "evoluem com o tempo e as mudanças sociais".

Além disso, referente à sua formação para melhores práticas como docente de Geografia, foram apontados pelos entrevistados à falta de capacitação dos professores, grade curricular, disciplinas específicas, aplicação dos conteúdos, divergência entre conteúdos acadêmicos com as escolas de base onde atuam após formação.

$O$ entrevistado $\mathrm{P} 6$ relatou que:

“Faltaram disciplinas específicas na grade curricular da instituição, como metodologia do ensino da geografia, instrumentação do ensino de geografia, em períodos próximos de modo a tornar mais habitual à prática docente no curso."

Enquanto o entrevistado P15 expôs que:

"Só nos damos conta dos problemas de nossa formação quando estamos enfrentando a realidade, em nosso campo de trabalho, a sala de aula. Faltaram mais aulas práticas, viagens de campo, direcionamento de atividades para a prática do ensino de fato. Pois cada um destes contribui significativamente para nossa formação. Em uma viagem de campo, por exemplo, é que podemos ver a teoria trabalhada ao longo do curso, sendo aplicada, e o curso de Geografia necessita bastante destas aulas de campo para que aja uma melhor formação profissional de seus alunos".

Ainda foi informado dentro da pesquisa que há falta de atualização de metodologias, categorias e conceitos da geografia, e maior aprofundamento no campo teórico. Foi também relatada por outros entrevistados uma satisfação acerca da aplicação dos conteúdos em sua formação.

\section{Quais as suas necessidades de formação?}

Muitos entrevistados informaram que a falta de tempo para dedicação a formação, maior acesso a eventos, graduação complementar e experiência em sala de aula são elementos que carecem de mais atenção nas suas formações.

$O$ entrevistado $\mathrm{P} 10$ relatou que:

"Não aprendi muita coisa na universidade por ter pouco tempo para me dedicar mais aos estudos. Aprendi muito mais na prática. Sinto necessidades de cursos de atualização". 


\section{O entrevistado P11 comentou que:}

"Durante a minha formação, tive a oportunidade de pagar disciplinas direcionadas a inclusão, como libras e educação especial. No entanto, ainda sinto que não estou completamente preparado para trabalhar com alunos especiais. Refiro-me principalmente em adequar as metodologias de ensino de geografia para que este aluno possa abstrair o máximo de conhecimento possível do conteúdo trabalhado. Esses tipos de práticas poderiam ser debatidas em um laboratório de ensino direcionado a licenciatura, coordenado pelo próprio departamento de Geografia. Outro ponto importante, é uma maior colaboração de disciplinas de geotecnologias, ainda pouco presentes na grade de formação dos licenciados, pois também somos pesquisadores e necessitamos destes recursos da cartografia digital e do geoprocessamento para uma representação socioespacial mais direcionada do conhecimento, tanto em pesquisas, como na sala de aula. Em nosso departamento, deveria haver um maior diálogo das disciplinas de geotecnologias com as de práticas de ensino de geografia."

\section{Enquanto o entrevistado P5 expôs que:}

"Uma graduação complementar, uma especialização na área de ensino e/ou mestrado. Um maior acesso aos eventos da área, com o intuito de trocas de experiências e atualização constante".

\section{CONCLUSÕES}

Os discentes da licenciatura buscam dentro da didática, estratégias que irão mediar o processo de ensino-aprendizagem, a partir do aperfeiçoamento das metodologias nos planos de aula, entre outras expectativas. $E$, anseiam que ao término da sua graduação, terão um aporte de mecanismos didáticos que proporcionarão sucesso na sua atuação como educador.

As disciplinas voltadas para a educação, como por exemplo, a didática pode contribuir no percurso da formação. Mas, por meio de alguns questionários aplicados pode se averiguar que alguns professores que atuam em sala de aula atualmente tiveram algumas frustrações com respeito a estas disciplinas, pois as fragilidades que surgiram em sua graduação, e, neste caso, a didática, tiveram lacunas, embora fossem mínimas, que proporcionaram dificuldades na prática docente.

Relembrando o que afirmou Luckesi (2012), no processo de formação é necessário que os futuros professores compreendam que ser "didático" está acima de mecanismos e ferramentas para ilustrar sua aula. Está estritamente relacionado a questões de caráter filosófico-político-educacional, que transpassam o ambiente escolar. 0 fato é que, se disciplinas como esta não se discutem estas reflexões, é possível que à medida que se formem mais professores, as ideologias de senso comum se reforcem dia após dia. Em outras palavras, é a Didática que dará ao professor as alternativas para obtenção do real processo de ensino-aprendizagem. Sem ela, não bastam todos os recursos tecnológicos ou conhecimento científico que possam tornar uma aula algo espetacular, pois não será possível alcançar a todos. A maioria, talvez, mas não todos. Nesse processo (ensinoaprendizagem), o conhecimento é algo a ser construído democraticamente para a formação crítica dos indivíduos. 
A formação docente atualmente enfrenta desafios e dilemas compatíveis com as exigências dos novos tempos. Com isso, amplia-se a diversidade de questões em torno desse tema, tornando-o abrangente, relacionando-se com os diferentes âmbitos da educação.

Dessa forma, Loureiro (2001) esclarece que a formação dos professores tem sido vista também com a panaceia para os males da educação e a sociedade. De acordo com Liston e Zeichner (1997), ao discutir as orientações comuns em torno da formação docente (acadêmicas; tecnológicas; personalista; prática e social reconstrucionista, dentre outras), além dessas orientações, há uma diversidade de termos usados como sinônimos de formação continuada: treinamento, capacitação, reciclagem, formação em serviços entre outros, cujos significados expressam diferentes práticas formativas.

\section{REFERÊNCIAS}

1. CANDAU, Vera Maria (org.). A Didática em questão. 33. ed. Petrópolis: Vozes, 2012. Cap. 1, p. 13.

2. DALBERIO, Maria Célia Borges. DALBERIO, Osvaldo. A formação docente: a mediação da didática para um ensino de melhor qualidade. Revista Ibero-americana de Educação. $\mathrm{n}^{\circ}$ 51/05, Fevereiro de 2010.

3. LUCKESI, Cipriano Carlos. O papel da didática na formação do educador. In: CANDAU, Vera Maria (Org.). A Didática em questão. 33. ed. Petrópolis: Vozes, 2012. Cap. 2, p. 26.

4. PONTUSCHKA, Níbia Nacib; PAGANELLI, Tomoko Lyda; CACETE, Núbia Hanglei. Para ensinar e aprender Geografia- $3^{\mathrm{a}}$ ed. - São Paulo: Cortez, 2009. - (Coleção docência em formação. Série Ensino Fundamental). 